его критическому мышлению с целью коррекции ее ситуативных смысловых установок.

$$
* * *
$$

1. Li, Zh. Vicarious traumatization: A psychological problem that cannot be ignored during the COVID-19 pandemic / Zhenyu Li, Jingwu Ge, Meiling Yang, Jianping Feng, Cunming Liu, Chun Yang // Brain, Behavior, and Immunity. - 2020. - Vol. 87. - P. 74; https://doi.org/10.1016/j.bbi.2020.04.047

2. Smith, B. M. Psychological inflexibility and intolerance of uncertainty moderate the relationship between social isolation and mental health outcomes during COVID-19 / Brooke M. Smith, Alexander J. Twohy, Gregory S. Smith // Journal of Contextual Behavioral Science. - Volume 18, October 2020. - Pages 162174. https://doi.org/10.1016/j.jcbs.2020.09.005

3. Захарова, Н.В. Смысловая регуляция тревожных ожиданий в период пандемии COVID-19: конспирологические тенденции / Н.В. Захарова, Т.И. Бонкало, Л.В. Бравве, Т.С. Сюняков, Д.Ф. Ковальчук // Здравоохранение Российской Федерации. - 2020. - Т. 64. - № 6. - С. 329-335; DOI: https://doi.org/10.46563/0044-197X-2020-64-5-329-335

4. Сорокоумова, Е.A. Понимание ситуации самоизоляции в период пандемии COVID-19 как фактор психологического благополучия специалиста / Е.А. Сорокоумова, Е.И. Чердымова, Е.Б. Пучкова, Л.В. Темнова, Т.И. Бонкало, Н.А. Вошева, В.М. Гребенникова // Здравоохранение Российской Федерации. - 2020. - Т. 64. - № 6. - С. 358-363; DOI: http://dx.doi.org/10.46563/0044-197X-2020-64-6358-363

\title{
Кокурина И.Г., Юсуфова О.О. \\ Макиавеллизм и особенности эмоционального реагирования на слова-стимулы трудовой деятельности у представителей малого бизнеса и наёмного персонала
}

Московский Государственный Университет имени М.В.Ломоносова (Россия, Москва)

doi: $10.18411 /$ sr-10-04-2021-72

\section{Аннотация}

Психология манипуляции по-прежнему остается одним из актуальных направлений исследований в области прикладной социальной психологии. В условиях кризиса рыночной экономики идеология использования манипулятивных приемов в потоках коммуникаций и взаимодействий в современном обществе оказывается самым экономным и быстрым способом достичь желаемого от партнеров в ситуации «здесь и теперь». Поскольку образ будущего кажется чем-то неопределенным и мало предсказуемым, то о последствиях манипуляций манипуляторы не задумываются. Руководители, подчиненные, клиенты, представители контролирующих органов - все участвуют в водовороте взаимного влияния, стремясь превратить любую ситуацию решения общей задачи в игру с односторонним выигрышем. Манипуляции, являясь специфическим методом влияния, выступают важной частью деловых взаимоотношений и активно используются в практике управления межличностными контактами в ситуации «здесь и теперь».

В современной литературе можно встретить две диаметрально противоположные позиции относительно вреда и пользы от использования манипуляции как инструмента воздействия на другого человека. В нашем исследовании мы попытались ответить на вопрос о том, способствует или препятствует установка на манипуляцию (макиавеллизм) занятиям индивидуальной предпринимательской деятельностью?

Ключевые слова: Макиавеллизм, эмоциональные оценки, коннотативные значения слов-стимулов, влияние, наемные работники, предприниматели (самозанятые), семантический дифференциал.

При манипуляции всегда эксплуатируются социально одобряемые потребности, благодарность (начальнику, коллеге, лидеру, духовному наставнику, фирме и т.д.) и 
удовлетворение - это те ключевые слова, которые могут быть использованы для описания стратегии манипуляции. Создание нужного настроения, чувство уверенности в собственной правоте создают необходимые условия для возникновения доверия у жертвы манипулятора. При этом порой именно Слово, за которым стоит та или иная ценность, является важным инструментом влияния. Слово, обозначающее в языке то или иное понятие и ценность имеет денотативное и коннотативное значение. Если денотативное значение отражает значение слова, имеющее объективное основание с которым все согласны, то коннотативное значение отражает эмоционально-оценочное дополнение к основному (денотативному) значению; это значение отражает эмоцию, сопряженную с индивидуальным опытом и характеристиками самого человека, которые отражаются в этом слове. По мнению исследователей эмоциональная сфера так называемых высоких макиавеллистов имеет свои особенности. Эти особенности мы искали в устойчивых различиях коннотативных значений слов-стимулов трудовой деятельности у высоких, средних и низких макиавеллистов в группах предпринимателей (самозанятых) и наемных работников.

В 90-ые годы в России на прилавках книжных магазинов появилось множество работ, посвященных психологии манипуляции, с описанием разнообразных приемов и технологий управления поведением другого человека.

Но наряду с описанием манипулятивных приемов и технологий в эти же годы в России появляются работы, посвященные особенностям личности самого манипулятора, так называемого высокого макиавеллиста. Эти работы написаны психотерапевтами, считавшими этих людей глубокими невротиками. (Р.Кристи и Ф.Гейс,1970; Э.Шостром,2008; Р.Мей,1997; А.Лоуэн,1997; ;Е.Л.Доценко, 1997; Н.МакВильямс,2015; Е.Т.Соколова 2015. и мн.др).

Основной психологической характеристикой макиавеллизма является: убеждение субъектов в том, что во время общения с другими людьми ими можно манипулировать; (Доценко, 1997). Уверенность макиавеллиста в своей правоте, правильности своих поступков оказывает внушающее воздействие на людей, с которыми он общается, делает его привлекательным в их глазах. Люди «ловятся» на спокойствие макиавеллиста, у них реже возникают неприятные ощущения, характерные для жертвы манипуляции, так как самого макиавеллиста не мучает совесть и тревога по поводу его действий. Кристи и Гейс назвали высокий уровень макиавеллизма «синдромом эмоциональной холодности», потому что социальная отстранённость является основной характеристикой подобных людей.(Christi \& Geis, 1970). Для макиавеллиста манипулировать людьми совершенно нормально и естественно. Из-за этого, во время общения у партнёров макиавеллиста возникает ложное чувство взаимопонимания с ним. Макиавеллизм как личностная характеристика в целом отражает неверие субъекта в то, что большинству людей можно доверять, что они альтруистичны, независимы, обладают сильной волей. (Christi \& Geis, 1970).

Изучение макиавеллизма как личностной черты началось в 70-ые годы XX века, в США двумя исследователями, Р.Кристи и Ф.Гейс, создавшими инструмент для оценки и измерения макиавеллизма. С помощью Мак- шкалы можно определить высоких, средних и низких макиавеллистов. (Christie \&Geis, 1970).

В последние десятилетия были проведены исследования макиавеллизма в рамках изучения так называемой темной триады. Оказалось, что макиавеллизм тесно связан с некоторыми устойчивыми личностными характеристиками, такими как психопатия и нарциссизм (Егорова М.С, Ситникова М.А, 2014 ,Корнилова Т.В 2015 и др.).

При высокой склонности к макиавеллизму, проявлении личностных черт, характерных для темной триады, а также демонстрации социальной отчужденности и 
склонности к эгоизму, высокие макиавеллисты будут наиболее эффективно и рационально действовать в условиях максимальной ситуативной и ролевой неопределенности - т.е. в начальный период жизни организации, а также в кризисных для организации ситуациях, когда требуется личность, которая способна поставить себя во главе организации, принять ключевые решения, доказать всему коллективу и другим членам руководства свою состоятельность. Напротив, в ситуациях стабильного существования организации такого рода высокие макиавеллисты будут скорее фактором, который сам вносит неопределенность и ролевой дисбаланс в существование организации, в то время как управленцы со средними показателями по Мак-шкале, склонные к социальному участию, но не приверженные к сильной межличностной вовлеченности, будут с большей степенью вероятности эффективно руководить коллективом. В ситуации стабильности для коллектива организации важна эмоциональная вовлеченность руководителя в дела организации, в настроения сотрудников, но при этом крайние показатели - эмоциональная и социальная отчужденность и холодность, характерная для высоких макиавеллистов, или чрезмерная межличностная вовлеченность и эмоциональная теплота, характерная для низких макиавеллистов, будут оказывать отрицательное влияние на управление организации. (Кокурина ,Бедненко,2006).

Ненси Мак-Вильямс описывает разновидность высокого макиавеллиста как типичного психопата \социопата\. По ее мнению, в основе данного характера лежат следующие базисные особенности психики и поведения.

1. Неспособность к человеческой привязанности

2. В общении с людьми организующим принципом поведения является принцип «сделать всех» или сознательно манипулировать другими.

3. Сниженная реактивность нервной системы выражается у них в постоянном стремлении к острым ощущениям и очевидной неспособности приобретать опыт через обучение.

4. Врожденная тенденция к агрессивности и к более высокому порогу возбудимости, которое способно приносить удовольствие. Психопат нуждается в резком и встряхивающем опыте для того, чтобы чувствовать себя... хорошо. Он неспособен членораздельно выражать свои чувства, проговаривать их. Вместо того, чтобы говорить - он действует.

5. Благодаря блокированию аффекта, у них отсутствует стремление к использованию языка для прояснения чувств.

6. Основным механизмом их психологической защиты является контроль, всемогущий контроль за другими людьми.

7. Ценность других людей у психопатов редуцируется до их полезности, в том числе согласия этих людей терпеть от них затрещины.

8. Нереально ждать любви от психопата /антисоциальной личности/, но можно заслужить их уважение упорным противостоянием и требовательностью к ним. Неподкупность, честность без компромиссов , позиция человека, граничащая с безразличием независимой силь. Такой способ поведения рекомендует психоаналитик для общения с макиавеллистом, чей характер отягощен ярко выраженной психопатией и нарциссизмом. (Н. Мак-Вильямс, 2015)

\section{Эмпирическое исследование}

В проведённом исследовании мы измеряли с помощью шкал СД эмоциональную оценку слов-стимулов в трудовой деятельности у респондентов с высоким, средним и низким уровнем макиавеллизма, а также выясняли на какие слова 
-стимулы эмоциональные реакции предпринимателей (самозанятых) значимо отличаются от эмоциональных реакций наемных работников с учетом их установки на макиавеллизм. Выборка состояла из 102 человек, из них самозанятых- 45 чел.; наемных - 57 чел. Среди них мужчин 33 человека и женщин 69 человек. По возрасту респондентов объединили в группы от 17 до 24 лет-66 человек, от 25 до 44 лет- 25 человек и от 45 лет до 65 лет -11 человек. Представителями малого бизнеса являлись самозанятые, а именно физические лица, самостоятельно осуществляющее на свой риск основанную на личном трудовом участии деятельность по оказанию услуг, выполнению работ для физических лиц, направленных на систематическое получение прибыли, не зарегистрированные в качестве индивидуального предпринимателя, не имеющих наёмных работников. В нашем исследовании это были косметологи, парикмахеры, мастера ногтевого сервиса, массажисты. Наёмные работники в нашем исследовании являлись студенты, получающие образование и имеющие подработку в сфере обслуживания ( продавцы-консультанты, репетиторы, агенты в сфере недвижимости, официанты, няни).

С помощью теста Р.Кристи и Ф.Гейс для измерения установки на макиавеллизм (перевод и адаптация Знакова, 2000) выборку разделили на три группы: с высокой , средней и низкой установкой на макиавеллизм. Методом СД Ч.Осгуда, (Социальная психология, практикум 2006 г.) исследовались эмоциональные реакции на 9 словстимулов (ценностей): Доверие, Контроль, Управление, Авторитет, Бизнес, Любовь, Работа, Закон. С помощью этого метода мы оценивали как общую суммарную эмоциональную оценку слов -стимулов по всем шкалам СД, так и эмоциональную оценку каждого слова-стимула по всем шкалам СД. Для обработки полученных результатов использовались программа SPSS Statistics 17.1 , описательные статистики (средние значения), тест Колмогорова-Смирнова на нормальность распределения, параметрические критерии (однофакторный дисперсионный анализ АНОВА, Т-тест сравнения средних) , непараметрические (коэффициент корреляции Спирмена, критерии Краскела-Уоллиса, Манна-Уитни).

В группах самозанятых и наемных работников, мы получили оценку эмоционального восприятия набора слов-понятий, составляющих ценностные аспекты трудовой деятельности .Этот набор был создан эмпирическим путем на основе личного опыта и прочитанной литературы, этот набор, по нашему мнению, отражает важную часть тезауруса трудовой деятельности людей.

\section{Описание результатов.}

В изучаемых группах по макиавеллизму статистически значимые различия были получены на три слова-стимула (ценности): Доверие, Работа, Закон.

Таблийа №1

Эмоциональная реакиия на слова-стимуль Доверие, Работа, Закон и установка на макиавеллизм

\begin{tabular}{|c|c|c|c|c|c|}
\hline $\begin{array}{c}\text { Низкая группа по } \\
\text { макиавеллизму }\end{array}$ & \multicolumn{2}{c|}{$\begin{array}{c}\text { Средняя группа по } \\
\text { макиавеллизму }\end{array}$} & \multicolumn{2}{c|}{$\begin{array}{c}\text { Высокая группа по } \\
\text { макиавеллизму }\end{array}$} \\
\hline Любовь & 2,05 & Любовь & 1,63 & Любовь & 1,58 \\
\hline Работа & $\mathbf{1 , 6 3}$ & Авторитет & 1,21 & Авторитет & 0,98 \\
\hline Доверие & $\mathbf{1 , 4 8}$ & Деньги & 0,92 & Доверие & $\mathbf{0 , 6 3}$ \\
\hline Авторитет & 1,39 & Доверие & $\mathbf{0 , 8 7}$ & Деньги & 0,63 \\
\hline Деньги & 1,25 & Работа & $\mathbf{0 , 7 3}$ & Работа & $\mathbf{0 , 4 8}$ \\
\hline Бизнес & 0,66 & Бизнес & 0,33 & Бизнес & 0,22 \\
\hline Управление & 0,47 & Контроль & 0,10 & Управление & 0,08 \\
\hline Контроль & 0,19 & Управление & $-0,03$ & Контроль & $-0,38$ \\
\hline Закон & $\mathbf{- 0 , 3 2}$ & Закон & $\mathbf{- 0 , 9 9}$ & Закон & $\mathbf{- 1 , 1 7}$ \\
\hline
\end{tabular}




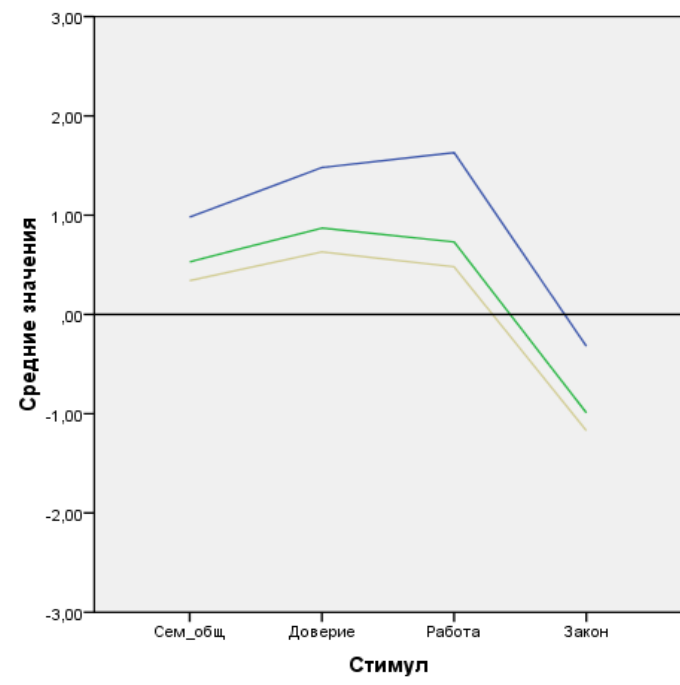

Группа по МАK

— Низкая

- Седняя для трех наиболее значимых слов: Доверие, Работа, Закон у респондентов с низкими, средними и высокими баллами по макиавеллизму.

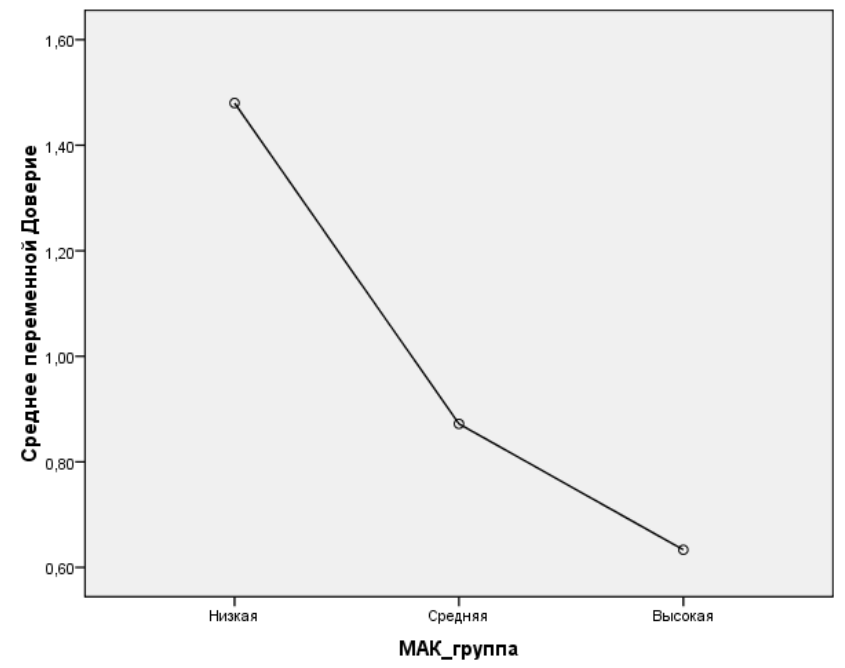

Рис. 2 Эмоцииональная реакциия на слово- стимул Доверие у низких, средних и высоких макиавеллистов.

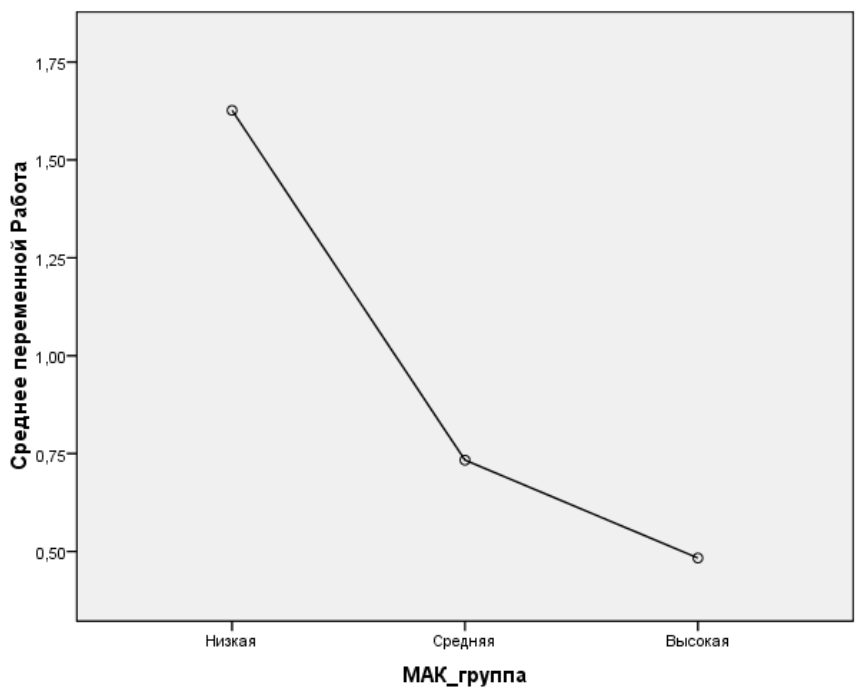

Рис.3 Эмоцииональная реакияия на слово- стимул Работа у низких, средних и высоких макиавеллистов. 
Результаты в группах предпринимателей (самозанятых) и наемных работников.

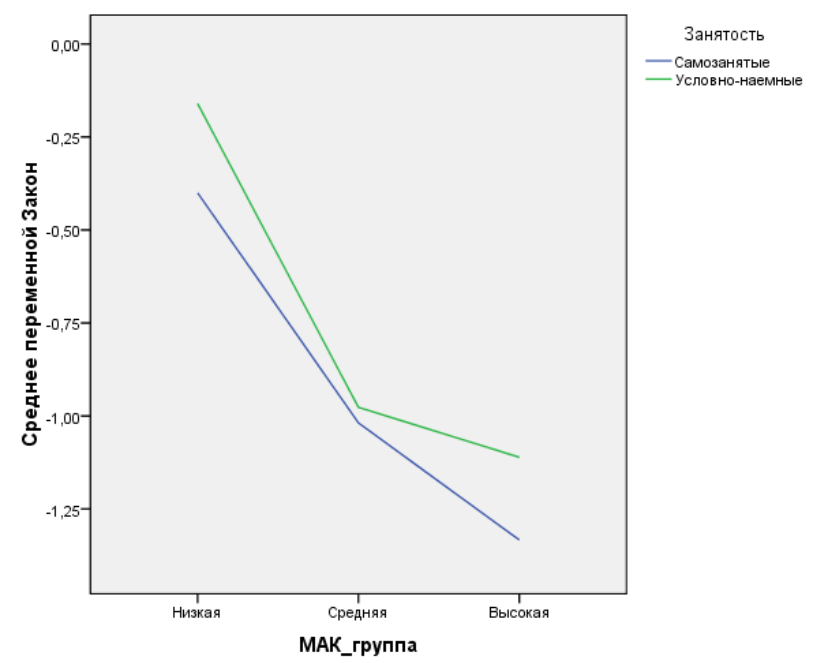

Рис.4. Эмоциональная реакция на слово-стимул Закон самозанятых и наемных респондентов, разделенных на группь по уровню макиавеллизма.

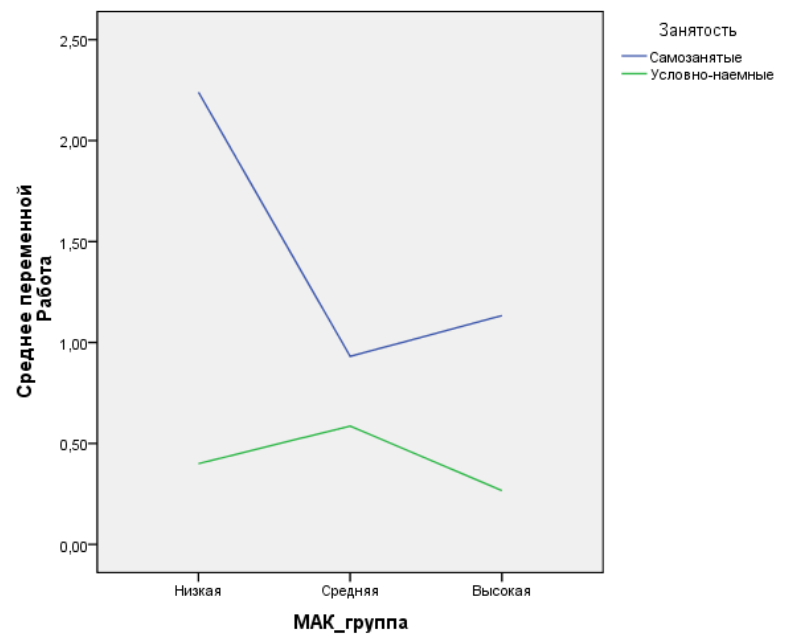

Рис.5 Эмоциональная реакциия на слово-стимул Работа самозанятых и условно-наемных респондентов, разделенных на группы по уровню макиавеллизма.

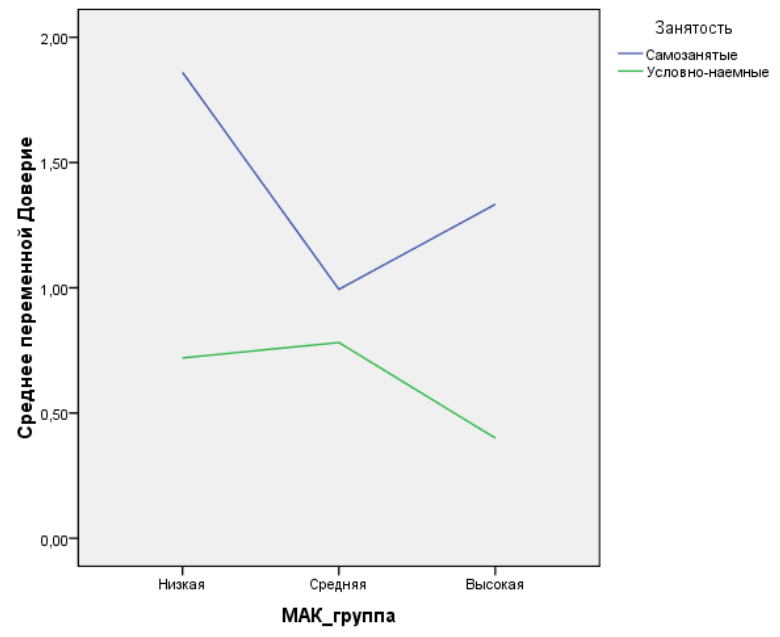

Рис. 6. Эмоциинальная реакцฺия на слово-стимул Доверие самозанятых и наемньх работников 
Выводы.

1) Результаты исследования свидетельствуют в том, что у высоких макиавеллистов эмоциональные реакции существенно менее выражены по сравнению со средними и низкими макиавеллистами, что совпадает с выводами зарубежных исследований об эмоциональной холодности или возможно об эмоциональной сдержанности высоких макиавеллистов, что на наш взгляд не одно и то же.

2) Диагностически значимыми словами-стимулами (из предложенного набора), отличающими высоких макиавеллистов от низких , а также самозанятых от наемных работников оказались всего три понятия : Работа, Доверие и Закон. Причем только Закон в нашей выборке оказался в отрицательной части шкал СД. А самые низкие оценки этому понятию дали высокие макиавеллисты в группе наемных работников.

3) Для низких и высоких макиавеллистов эмоционально более привлекательной формой работы оказалась социально-экономическая позиция быть самозанятым, а не наемным работником. Наемная работа оказалась наименее предпочтительной в эмоциональных оценках как у высоких так и у низких макиавеллистов. Полученные результаты требуют подтверждения на других выборках по возрасту, уровню образования и профессий у самозанятых и наемных работниках.

$$
* * *
$$

1. Christie R., Geis,F. Studies in Machiavellianism. N.Y.: Academic Press, 1970

2. Доценко Е. Л. Психология манипуляции: феномены, механизмы и защита. - М.: ЧеРо, Издательство МГУ, 1997.

3. Знаков В.В. Макиавеллизм: психологическое свойство личности и методика его исследования, Психологический журнал, 2000, том 21, №5, с. 16-22

4. Егорова М.С. Макиавеллизм в структуре личностных свойств // Вестник Пермского государственного педагогического университета. 2009. № 1/2,

5. Кокурина И.Г., Бедненко А.В. Манипулятивная установка в профессии менеджера.// Вестник Моск. ун-та.Сер.14.Психология.2006 №3 С.46-58

6. Корнилова Т.В., Чумакова М.А., Гаджиева Г.И Кросс-культурное исследование связей Темной Триады с эмоциональным интеллектом (на российской и азербайджанской выборках) // Психологические исследования Тхостов А.Ш. Депрессия и психология эмоций // Депрессия и коморбидные расстройства; Под ред. А. Б. Смулевича. 1997. URL: http://www.psychiatry.ru/lib/1/book/5/chapter/12 (дата обращения: 06.08.2018).

7. Lewin,A,Y.,Stephens,C,U. CEO attitudes as determinants of organizational design: An integrated model // Organization Studies.1994, vol.80 (3, Pt.1)

8. Мак-Вильямс Понимание структуры личности в клиническом процессе.- М:Независимая фирма «Класс», 2015-592с

9. Шостром Э. Человек-манипулятор. М.: Апрель-Пресс, Психотерапия, 2008

10. Соколова Е.Т. Клиническая психология утраты Я. М.: Смысл, 2015. — 895 с

11. Юсуфова О.О. Особенности установки на доверие у представителей малого бизнеса и наёмного персонала, Магистерская диссертация, МГУ им. М.В. Ломоносова, Москва, 189 с., 5.06 .2019 г

\section{Пекарева А.C. \\ Страхи и тревожность у детей старшего дошкольного возраста}

ФГАОУ ВО «Южный федеральный университет» (Россия, Ростов-на-Дону)

doi: 10.18411/sr-10-04-2021-73

Научный руководитель Новохатько Е.Н.

\section{Аннотация}

В статье рассматриваются теоретические проблемы страха и тревожности у детей старшего дошкольного возраста. Проблема страхов недостаточно актуальна и в 